International Journal of Engineering \& Technology, $7(3.12)(2018) 594-600$
International Journal of Engineering \& Technology
SPC
Website: www.sciencepubco.com/index.php/IJET
Research paper

\title{
Simulation of Multipurpose Reservoir Operation with Hedging Rules
}

\author{
K Sasireka $^{1^{*}}$, T R Neelakantan ${ }^{2}$, S Suriyanarayanan ${ }^{3}$ \\ ${ }^{1,3}$ School of Civil Engineering, SASTRA Deemed University, Thanjavur 613401, India \\ ${ }^{2}$ Department of Civil Engineering, Kalasalingam Academy of Research and Education, \\ Kalasalingam Deemed University, Krishnankoil, India. \\ *Corresponding Author Email: sasireka@civil.sastra.edu ${ }^{l}$ \\ neelakantan@klu.ac.in ${ }^{2}$,suriyanarayanan@civil.sastra.edu ${ }^{3}$
}

\begin{abstract}
Reservoir operation plays an important role in the economic development of a region. The storage reservoirs are not only useful for supplying water for municipal and irrigation purpose, but also act as a protection barrier form flood, and the stored water can be used for generation of electricity power as well. To meet the objectives for which the reservoir was planned, it is vital to formulate guidelines for the operation of reservoir. This can be achieved by systematic operation of the system, and by the use of systematic and simplified rule curve for the operation of reservoir. Hedging rules are popular in drinking and irrigation water supply. Application of hedging is now gaining focus for hydropower power reservoir operation. In the present study, attempt has been made to formulate a new operating rule for multipurpose reservoir using hedging rules and the developed model was applied to a case study of Bargi reservoir in the Narmada basin in India. In order to increase the reliability of water supply for municipal, irrigation and average annual power production, the new operating rule has been developed using Standard Operation Policy (SOP) and hedging rule according to the priority of release for different purposes. The hedging rule based simulation model satisfies $97.5 \%$ of municipal water supply which is more than $8.25 \%$ of the present operational policy. The spill of the reservoir is decreased by $57 \%$ compared to present policy. The performances of different hedging rules were compared with that of a new standard operating policies and the superiority of the hedging rules are discussed in this paper.
\end{abstract}

Keywords: Standard Operation Policy, Standard Hedging rule, multipurpose reservoir operation, hydropower

\section{Introduction}

Reservoir problems contain inherent uncertainty, the random nature of reservoir inflows and other related hydrologic variables are another important characteristics of reservoir analysis. The development of optimal operating rules for reservoir has been an active area of research in water resource management. Release based statistics are used to measure the performance of reservoir operation [1]. In the last 5 decades, many researches have been reported on this subject and detailed literature reviews were provided by Yeh [2], Simonovic [3], Wurbs [4], Labadie [5]. The major task of reservoir operation is to decide how much water should be released in the current period and how much should be retained in stock within the reservoirs for future use, give some available and/or forecast information at the beginning of the current time period [6].

Reservoir operation using standard operating policy (SOP) is one of the earliest and simplest policy which aims to satisfy the entire demand, if available water is sufficient to meet the demand, if not, whatever the available water is utilized to meet the demand and SOP is not consider preserving water for future requirements [7]. However, this policy lacks flexibility and is not suited for reservoir operation during drought periods or when the drought is impending, since it is likely to increase the maximum single period deficit (vulnerability). But Hedging rule allows to store water for future purpose by accepting small current deficits to guard against unacceptable large deficits that are likely to occur

in future. Hedging rule distributes the deficits in water supply across time to minimize the impact of drought. Thus, hedging provides insurance for high-valued water uses, where reservoirs have low refill potentials or experience highly uncertain inflows [8].

Hashimoto et al. [9] showed that the hedging rules were more appropriate when the loss function was non-linear. Optimization of a hedging rule for a water supply reservoir was demonstrated by Shih and ReVelle ([10], [11]). Optimization of water supply reservoir system using hedging rule is extensively reported in many literatures ([12], [13] and [14], etc.,). Different forms of hedging rules used for domestic and irrigation supply for the past few decades and Neelakantan and Sasireka [15] review paper and Sasireka and Neelakantan [16,17]shows different forms of hedging rules proposed for domestic, irrigation and hydropower generation purpose. Karamouz et al. [18] developed a contingency planning scheme by incorporating hedging rule in the operation of reservoirs in drought periods to reduce the effect of water deficit. Almost all the reported works which used hedging rule for reservoir operation considered either drinking water demand or irrigation demand or both together. However, it seems hedging rule was not applied to hydropower generation reservoir. 


\section{Study Area}

Study area selected for the present study is the Bargi dam (later renamed as Rani Avanti Bai Sagar Project) which has been constructed across the river Narmada in India. The latitude and longitude of the dam is $22^{\circ} 56.5^{\prime} \mathrm{N}$ and $7955.5^{\prime} \mathrm{E}$ respectively. The gross, the live and the dead storage capacities of the reservoir are $3.92 \times 10^{9} \mathrm{~m}^{3}, 3.18 \times 10^{9} \mathrm{~m}^{3}$ and $0.704 \times 10^{9} \mathrm{~m}^{3}$ respectively. The maximum water level, full reservoir level and the dead storage level of the reservoir are at $425.70 \mathrm{~m}, 422.76 \mathrm{~m}$ and $403.55 \mathrm{~m}$ respectively. The project is envisaged as a multi-purpose project, meant to serve water supply for domestic and industrial purposes, irrigation and the generation of hydropower. Presently, one left bank canal system which consists of two units of capacity of 45 MW each are operational. The monthly water requirement from the reservoir through the left bank canal for domestic water supply is $4.5 \times 10^{6} \mathrm{~m}^{3}$. The annual water requirement from the reservoir for irrigation is $2160.1 \times 10^{6} \mathrm{~m}^{3}$ and annual firm energy requirement of the reservoir is $363 \mathrm{MkWh}$. The monthly evaporation rate, Mean monthly inflow and monthly target demands for irrigation and hydropower are presented in Table 1. In this system irrigation water supply is given higher priority in the months from March to June and in other months hydropower production is given higher priority.

\section{Methodology}

All the above literatures except Zeng et al [19] and Neelakantan and sasireka [20] shows that the different types of hedging rules are applied for domestic, industrial and irrigation supply. Hence, in this study it is proposed to develop new operating rules for multipurpose reservoir using different forms of hedging rule. In case of rservoir operation of domestic and irrigation supplies, the water demand is fixed and the release is based on the demand and water availability in the reservoir. But in the case of hydropower reservoir operation, the power demand ' $\mathrm{P}$ ' is constant and which is calculated from the equation $P \propto Q H$ and water demand is variable. Due to nonlinearity of discharge $(\mathrm{Q})$ and Head $(\mathrm{H})$, SOP (Figure 1) used for municipal and irrigation purpose is not suitable for hydropower reservoir operation and hence new form of SOP for hydropower ([20]) is used as a benchmark to compare the performance of the reservoir operation developed with the help of the hedging rule. Figure 2 shows the new form of $\mathrm{SOP}_{\mathrm{P}}$ (Standard Operating Policy for power production) for hydropower reservoir operation. In Figure 2, between P1 and P2, the demand and release are falling as the head is increasing and after P2, the demand and release become constant. ' $\mathrm{S}$ ' is a quantity of available-water in the reservoir at which releasing all the available-water produces the target power or demand power $\mathrm{K}$ is the capacity of the reservoir

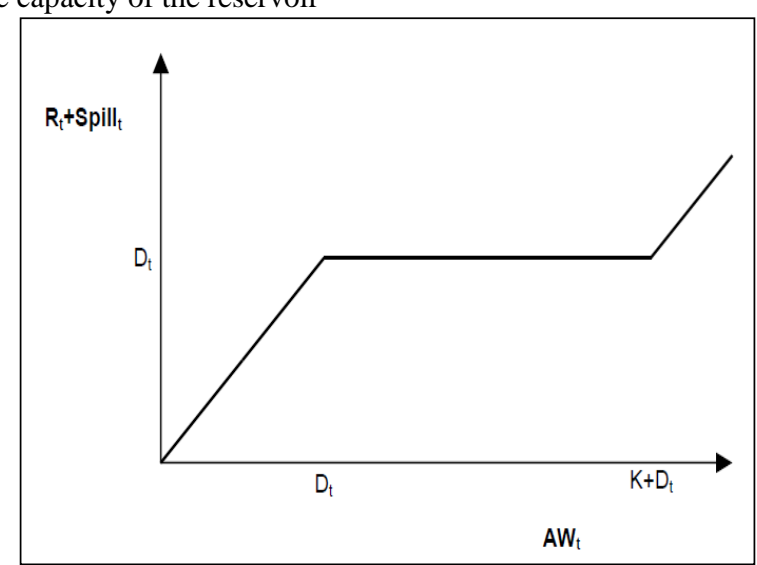

Fig. 1: SOP for municipal and irrigation supply

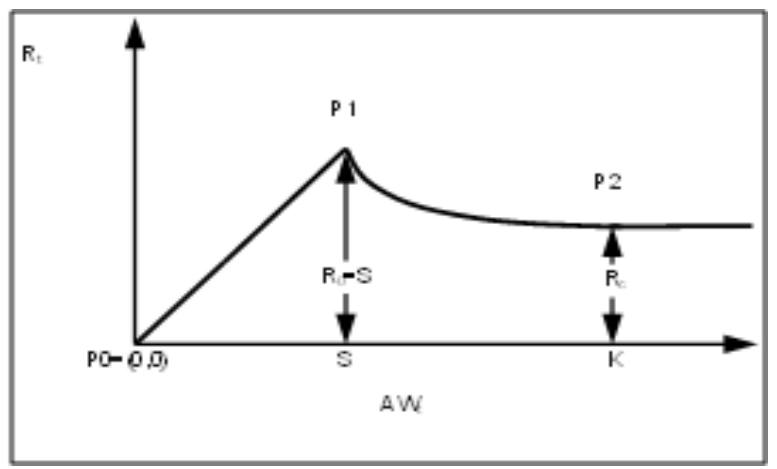

Fig. 2: Standard Operating Rule $\left(\mathrm{SOP}_{\mathrm{P}}\right)$ for Hydropower Generation

In the multipurpose reservoir operation, water release is decided based on the priority of the (Irrigation and Hydropower) demand, but municipal water supply demand should be satisfied for all months based on the available water in the reservoir. Operation of multipurpose reservoir is too complex, hence single policy is not sufficient to improve the performance of the reservoir. An attempt is made in this study by applying SOP and the hedging rule for municipal and irrigation supply and $\mathrm{SOP}_{\mathrm{P}}$ and hedging rule for hydropower supply based on priority to improve the performance of the reservoir. In this study, one point hedging rule [10] shown in Figure 3 is used for the operation of municipal and irrigation water supply. In order to avoid continuous power deficit, if power that can be generated using the available water is less than the minimum required power, instead of releasing the available water it can be saved for future purposes, which is depicted in Figure 4. through a modified SOP

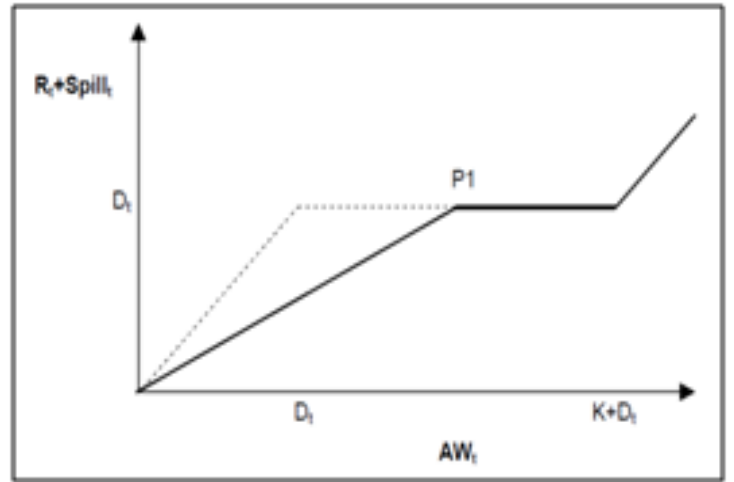

Fig. 3: One-point linear hedging rule for municipal supply

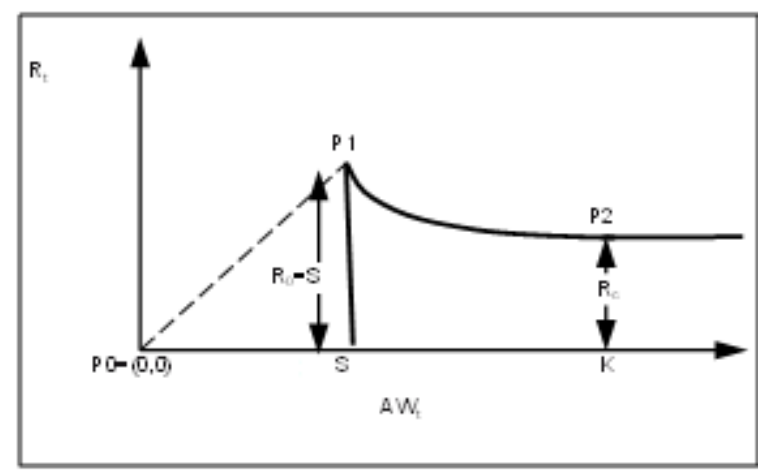

Fig. 4: Modified Standard Operating Rule $\left(\mathrm{MSOP}_{\mathrm{P}}\right)$ for Generating only the minimum demand Power [20]

The methodology adopted for working of the multipurpose reservoir using hedging rule is described in the form of a flow chart is shown in Figure 5. Figure 6 and Figure 7 shows the modified one point hedging rule and standard hedging rule for hydropower operation respectively. Shih and ReVelle [10] highlighted the one point hedging rule shown in Figure 3 for municipal water supply. When the starting point $\mathrm{P} 1$ of two-point hedging rule is the origin, the two-point linear hedging rule reduces to the one-point hedging. In the SOP, for the segment 
(available water at time ' $\mathrm{t}$ ') $A W_{t} \leq D_{t}$ (demand at time ' $\mathrm{t}$ ') the release is represented by a 45 -degree line (slope equal to 1.0) in the rule graph. However, in the one-point hedging rule, the line is having a slope of less than 1.0 until $A W_{t}=P 1_{x}$.

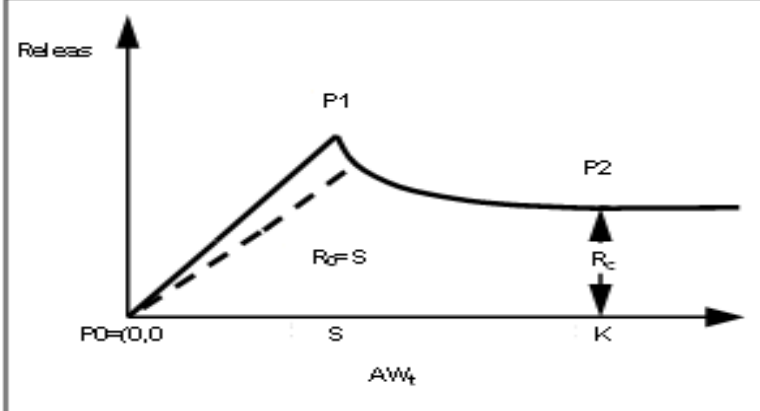

Fig. 6: One-point linear hedging rule for hydropower reservoir

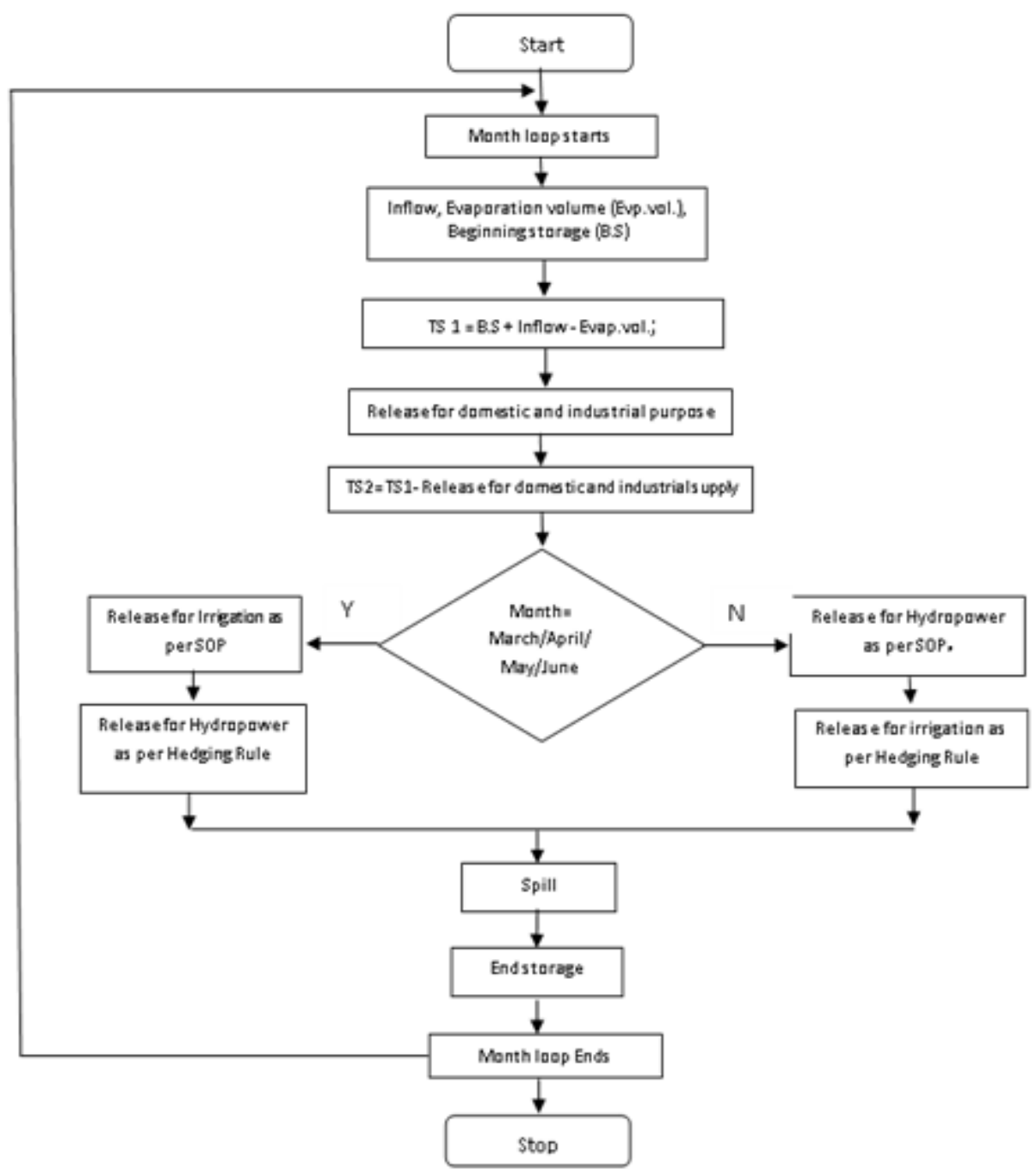

Where, TS 1- Temporary storage 1, TS 2 - Temporary storage 2

Fig. 5: Methodology adopted for the Bargi reservoir

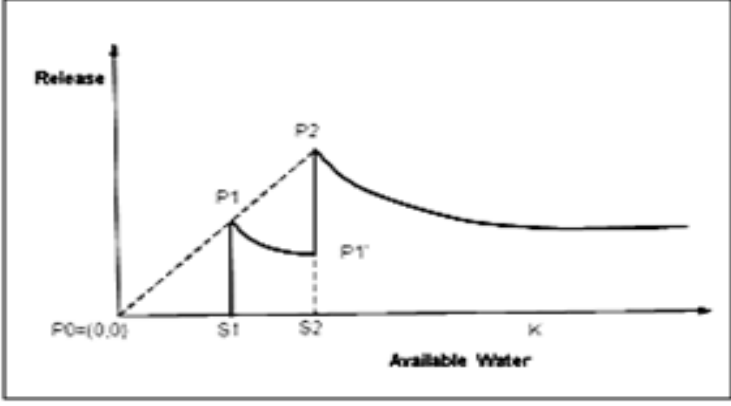

Fig. 7: Standard hedging rule for hydropower reservoir [20]

\section{Simulation Model}

The newly developed model is applied to the Bargi reservoir taken as a case study. Monthly inflow data from June 1951 to December 1990 was used in this study. The total number of monthly data used in this study is 475 . The continuity equation used for simulation model is given below

$\mathrm{S}_{\mathrm{mon}+1}=\mathrm{S}_{\mathrm{mon}}+\mathrm{I}_{\mathrm{mon}}-\mathrm{Evp}_{\mathrm{mon}}-\mathrm{R}_{\mathrm{mon}}-\mathrm{Spill}_{\mathrm{mon}}, \forall \mathrm{mon}$

where, $R_{\text {mon }}$ is the release made for municipal and irrigation requirement and power generation, $\mathrm{I}_{\text {mon }}$ is the inflow into the reservoir and $\mathrm{Evp}_{\mathrm{mon}}$ is monthly evaporation volume, which is calculated from the water spread area (WSA) multiplied by the rate of evaporation. The WSA equation is given below. $W S A=\left(-8 \times 10^{-6} \times S^{2}\right)+(0.113 \times S-39.854)$ 
where $\mathrm{S}=($ Beginning storage + End storage $) / 2$

By using power equation $\mathrm{P}=\mathrm{CQH}$, minimum release (releasing of entire quantity will produce the demand power) was found for the known demand power, where ' $\mathrm{C}$ ' is the constant which includes the specific weight of water, unit conversion factor and the efficiency $(60 \%)$ of the turbine, ' $Q$ ' is release in $10^{6} \mathrm{~m}^{3}$ and ' $\mathrm{H}$ ' is head (mean head). When the water level is reached to a maximum capacity, the release corresponding to the maximum capacity was found using dam data. Using the Bargi dam hydraulic data, the release equation is obtained, which shows the releationship between release for various power produciton and available water. When the avilable water is increases, the release required to produce the minimum power is get decreased due to nonlinearity of discharge and head. Table 2. Shows the values of the minimum release and release corresponding maximum capacity. From Table 2. it is clear that the minimum power demand of the Bargi reservoir for all month is $20 \mathrm{MkWh}$. The minimum available water required to produce $20 \mathrm{MkWh}$ is $407 \times 10^{6} \mathrm{~m}^{3}$ and it is reduced to $255 \times 10^{6} \mathrm{~m}^{3}$ when the available water is reached to maximum capacity of the reservoir.

Table 2: Minimum release corresponding to the demand power

\begin{tabular}{|c|c|c|}
\hline $\begin{array}{c}\text { Demand } \\
\text { Power } \\
(\mathbf{M k W h})\end{array}$ & $\begin{array}{c}\text { Min. release for demand } \\
\text { power }\left(\mathbf{1 0}^{\mathbf{6}} \mathbf{~ m}^{\mathbf{3}}\right)\end{array}$ & $\begin{array}{c}\text { Release corresponding to } \\
\text { Maximum capacity } \\
\left.\mathbf{m}^{\mathbf{3}}\right)\end{array}$ \\
\hline 20 & 407 & 255 \\
\hline 30 & 585 & 378 \\
\hline 40 & 747 & 495 \\
\hline 60 & 1080 & 750 \\
\hline
\end{tabular}

Several simulations were analysed using different forms of hedging rule to maximize the average monthly power production, to minimize average monthly spill, to increase the reliability of water supply for municipal, irrigation and power. The following cases are attempted in this study area. In all the cases the municipal supply is given first priority and it should be satisfied for all the months based on the available water in the dam.

Case 1: Release is made based on SOP for municipal and irrigation supplies (Figure 1) and $\mathrm{SOP}_{\mathrm{p}}$ for hydropower generation (Figure 2). For the month of March, April, May, June higher priority is given for irrigation and for other months hydropower is given higher priority.

Case 2: Release is made based on SOP for municipal and irrigation (Figure 1) and $\mathrm{MSOP}_{\mathrm{P}}$ (Figure 4) for hydropower as per the priority basis. In this case, system should be considered to produce minimum demand power of $20 \mathrm{MkWh}$ otherwise zero power. The minimum water stored can be utilized to meet the irrigation demand or future demand.

Case 3: In the month of March, April, May and June release are made for irrigation as per SOP and one-point hedging rule (Figure 5 ) is applied for hydropower and vice versa. By varying the slope of the line from origin of the one- point hedging rule from $35^{\circ}$ to $44^{\circ}$, the results are obtained.

Case 4: One- point hedging rule is applied for irrigation release and release for hydropower is based on a standard hedging rule. Hydropower release is based on $\mathrm{SOP}_{\mathrm{P}}$, when the release is equal to minimum release which is shown in Table. 2, the standard hedging rule is applied by shifting the minimum release to higher value. For example, if $407 \times 10^{6} \mathrm{~m}^{3}$ water is sufficient to produce $20 \mathrm{MkWh}$, the release is made when the available water is increased to $507 \times 10^{6} \mathrm{~m}^{3}, 607 \times 10^{6} \mathrm{~m}^{3}$ etc. Hence, head is increased and thereby release is reduced, the saved water can be used for future purpose.

Case 5: In the case of hydropower release, hedging increases head and thereby release can be decreased. Hence, in this case, two attempts were made (i) by applying hedging for hydropower alone for all months and (ii) by applying hedging for hydropower alone for the months except from March to June.

\section{Results and Discussions}

The results obtained by applying the above methodology to the Bargi reservoir system as a case study is discussed here. A time reliability performance index for municipal water supply, irrigation and target energy is calculated by using the equation given below.

\section{Time reliability index $(R I)$ Total Number of failure month $=1-\frac{\text { Total number month in the computational period }}{\text { Tom }}$}

In this model, if the release is not sufficient to satisfy the demand release, then the month is considered as a failure month. SOP for municipal and irrigation supply and $\mathrm{SOP}_{\mathrm{P}}$ for hydropower release is considered as a benchmark to compare the results obtained from different cases. Case 1 (SOP \& $\mathrm{SOP}_{\mathrm{P}}$ ) is performing better in the case of energy production, but time reliability of municipal supply, irrigation and target energy is comparatively more in case

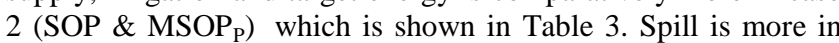
Case 2 by comparing Case 1, due to the curtailing of water, when the available water is not sufficient to produce the minimum demand energy (20 MkWh). But in the case of present policy [19], spill is more and reliability of municipal water supply is less compare to case $2\left(\mathrm{SOP}\right.$ and $\left.\mathrm{MSOP}_{\mathrm{P}}\right)$. Table. 4 shows that the results obtained from case 3 , where one-point hedging rule applied to both irrigation and hydropower as per the priority basis, in which slope of SOP and SOP $\mathrm{p}$ vary from $35^{\circ}$ to $44^{0}$. The average monthly energy production and reliability of target energy is more for the maximum slope and for all other performances minimum slope $\left(35^{\circ}\right)$ gives better result.

Table 5 shows the results obtained from the one-point hedging rule for irrigation and standard hedging rule for hydropower (case 4). The average energy production is maximum when the irrigation release is at the slope of $36^{\circ}$ and $37^{\circ}$ with higher value of minimum release (minimum release $+1200 \times 10^{6} \mathrm{~m}^{3}$ ). The improvement in average energy production is negligible when the hedging trigger value is increased between $600 \times 10^{6} \mathrm{~m}^{3}$ to 1000 $x 10^{6} \mathrm{~m}^{3}$, hence the results were not shown in Table. 5. The spill considerably reduced with higher value of minimum release irrespective of the slope of the curve. Reliability of municipal, irrigation supply and target energy production is higher when the hydropower release is shifted to minimum higher value (minimum release $+100 \times 10^{6} \mathrm{~m}^{3}$ ) and irrigation release are made by using maximum slope. Average monthly irrigation release is maximum when the irrigation release is at $35^{\circ}$ slope and hydropower release at shifting of minimum release to minimum higher value. Average monthly irrigation release is maximum for the lesser slope and shifting to minimum trigger value. Average monthly energy is not considerably increased much from all above cases. Hence another trials case 5 (i) is attempted to increase the average energy production by allowing the irrigation release by SOP and hydropower release by standard hedging rule for all months and case 5 (ii) is attempted by allowing the irrigation release by SOP and hydropower release by standard hedging rule except for the months from March to June. The average monthly energy production is increased to $30.46 \mathrm{MkWh}$ when the standard hedging rule is applied to hydropower for all months which is shown in Figure 8. The spill also reduced to $57 \%$ compared to present operating policy. Figure 9 to Fig 14 shows the performance of the reservoir for different cases. Figure 10 shows that the average energy production is maximum in case 5(i) compared to all other cases and it is almost same compare to present policy and also it satisfies the annual firm energy requirement $(363 \mathrm{MkWh})$ of the reservoir. Figure 10 shows that the spill is reduced much in case5 (i) compared to all other cases and as well as with the present policy. The RI of municipal supply is $94.74 \%$ for all the cases except case 1 and case 3. However, for the present policy RI of municipal supply is $88.60 \%$. Compared to all other cases, case 2 provides more RI of energy production, more RI of irrigation release and more average 
monthly irrigation release. However, irrigation release is lesser

than the present policy and it satisfies $84 \%$ of the irrigation

requirement.

Table 3: Comparison of result from Case1 and Case 2 with present operating policy

\begin{tabular}{|c|c|c|c|}
\hline & Case 1 (SOP) & Case 2 (MSOP $)$ & Present Policy \\
\hline Average monthly power $(\mathrm{MkWh})$ & 25.90 & 25.04 & 30.80 \\
\hline Average monthly spill $\left(10^{6} \mathrm{~m}^{3}\right)$ & 88.02 & 94.62 & 172.89 \\
\hline Reliability for municipal supply $(\%)$ & 92.63 & 94.74 & 88.60 \\
\hline Reliability for Irrigation (\%) & 69.47 & 74.74 & 73.90 \\
\hline Reliability for target energy $(\%)$ & 62.53 & 66.95 & 68.40 \\
\hline Average monthly Irrigation release $\left(10^{6} \mathrm{~m}^{3}\right)$ & 136.18 & 151.22 & 163.07 \\
\hline
\end{tabular}

Table 4: Performance of the reservoir from Case 3 for different slopes

\begin{tabular}{|c|c|c|c|c|c|c|c|c|c|c|}
\hline Slope in $\left(^{(}\right)$ & $\mathbf{3 5}$ & $\mathbf{3 6}$ & $\mathbf{3 7}$ & $\mathbf{3 8}$ & $\mathbf{3 9}$ & $\mathbf{4 0}$ & $\mathbf{4 1}$ & $\mathbf{4 2}$ & $\mathbf{4 3}$ & $\mathbf{4 4}$ \\
\hline $\begin{array}{c}\text { Average monthly Energy } \\
(\mathrm{MkWh})\end{array}$ & 25.81 & 25.82 & 25.83 & 25.83 & 25.84 & 25.85 & 25.86 & 25.87 & 25.88 & 25.89 \\
\hline $\begin{array}{c}\text { Average monthly spill }\left(10^{6}\right. \\
\left.\mathrm{m}^{3}\right)\end{array}$ & 89.54 & 89.40 & 89.30 & 89.14 & 88.99 & 88.83 & 88.68 & 88.53 & 88.37 & 88.18 \\
\hline $\begin{array}{c}\text { Reliability for Municipal } \\
\text { supply (\%) }\end{array}$ & 94.32 & 94.32 & 94.11 & 94.11 & 94.11 & 93.89 & 93.89 & 93.89 & 93.89 & 93.89 \\
\hline Reliability for Irrigation (\%) & 70.95 & 70.53 & 70.32 & 69.68 & 69.68 & 69.47 & 69.47 & 69.05 & 69.47 & 69.47 \\
\hline $\begin{array}{c}\text { Reliability for target power } \\
(\%)\end{array}$ & 61.89 & 62.11 & 61.89 & 62.11 & 62.11 & 62.11 & 62.32 & 62.32 & 62.32 & 62.32 \\
\hline $\begin{array}{c}\text { Average monthly Irrigation } \\
\text { release }\left(10^{6} \mathrm{~m}^{3}\right)\end{array}$ & 137.7 & 137.7 & 137.6 & 137.6 & 137.5 & 137.4 & 137.3 & 137.2 & 137.1 & 136.9 \\
\hline
\end{tabular}

Table 5: Monthly average energy production in MkWh from Case 4

\begin{tabular}{|c|c|c|c|c|c|c|c|c|c|}
\hline 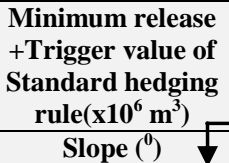 & 100 & 200 & 300 & 400 & 500 & 600 & 1000 & 1100 & 1200 \\
\hline 35 & 25.39 & 25.89 & 25.95 & 26.01 & 26.16 & 26.24 & 26.47 & 26.47 & 26.52 \\
\hline 36 & 25.47 & 25.96 & 26.01 & 26.09 & 26.24 & 26.32 & 26.56 & 26.56 & 26.63 \\
\hline 37 & 25.47 & 25.94 & 26.01 & 26.09 & 26.24 & 26.32 & 26.56 & 26.56 & 26.62 \\
\hline 39 & 25.46 & 25.96 & 26.01 & 26.09 & 26.23 & 26.31 & 26.55 & 26.55 & 26.61 \\
\hline 40 & 25.45 & 25.96 & 26.01 & 26.08 & 26.23 & 26.30 & 26.55 & 26.55 & 26.61 \\
\hline 41 & 25.45 & 25.95 & 26.00 & 26.08 & 26.22 & 26.30 & 26.55 & 26.55 & 26.60 \\
\hline 42 & 25.44 & 25.95 & 26.00 & 26.08 & 26.22 & 26.29 & 26.55 & 26.55 & 26.60 \\
\hline 43 & 25.44 & 25.95 & 26.00 & 26.07 & 26.22 & 26.29 & 26.54 & 26.54 & 26.60 \\
\hline 44 & 25.44 & 25.94 & 25.99 & 26.07 & 26.22 & 26.29 & 26.54 & 26.54 & 26.60 \\
\hline
\end{tabular}

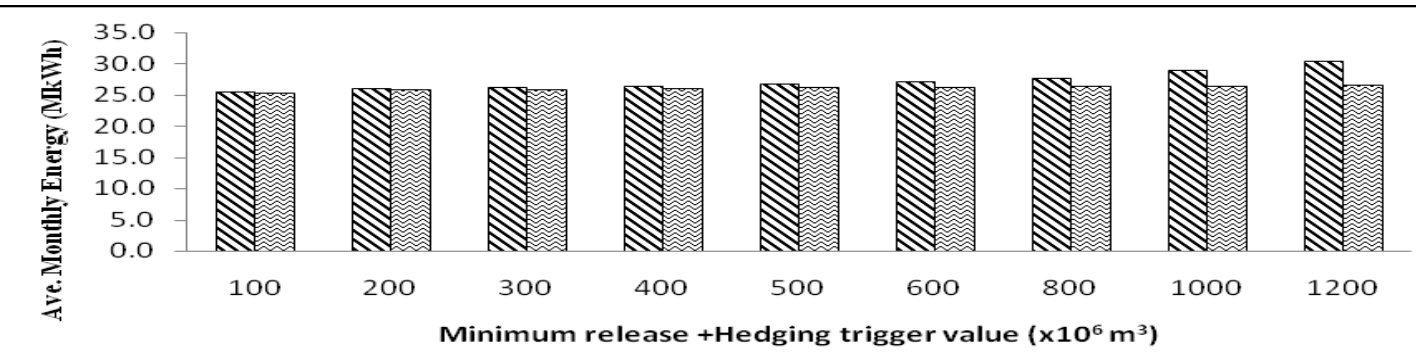

\$ Hedging for all months (MkWh)

Fedging for March-June (MkWh)

Fig. 8: Comparative graph for average monthly energy in MkWh from case5(i) \&(ii)

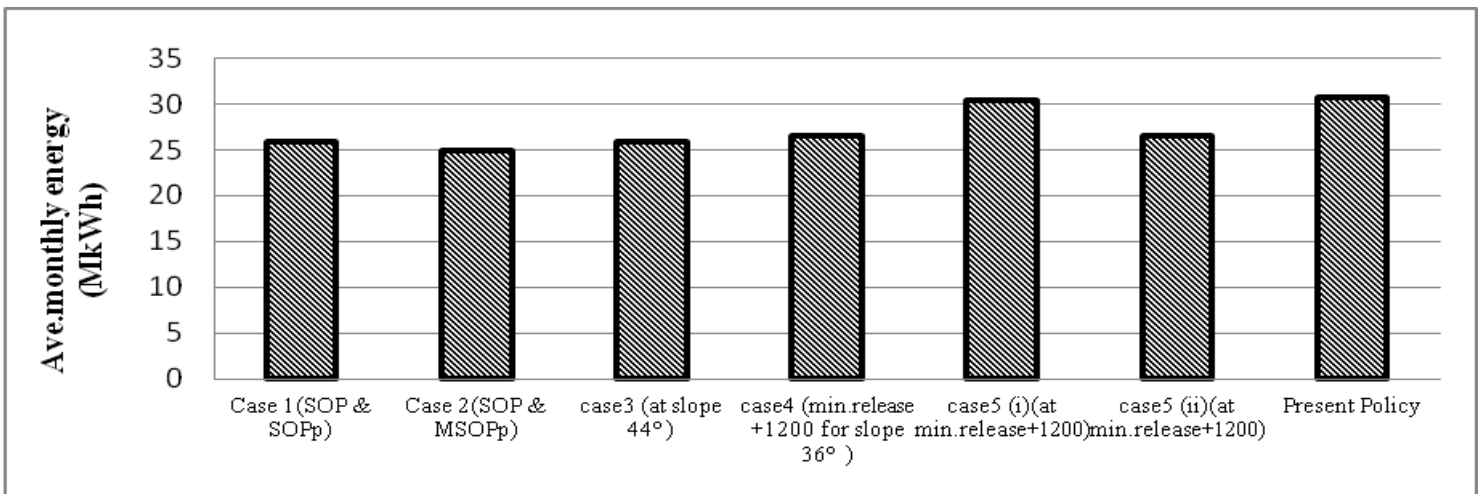

Fig.9: Comparative plot of average monthly energy production from all the cases 


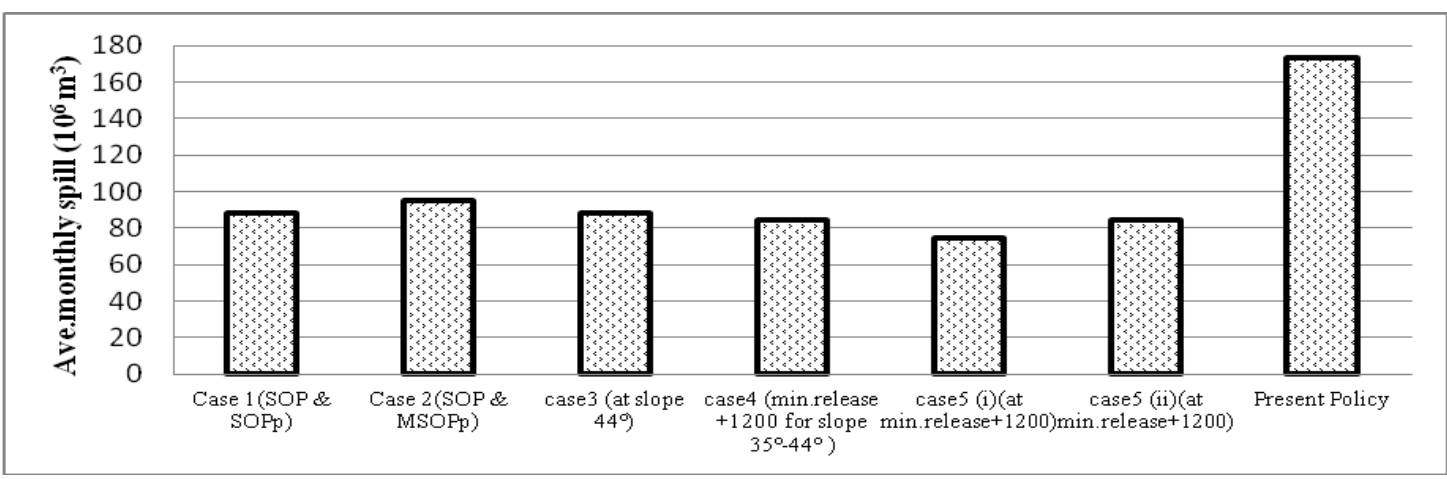

Fig. 10: Comparative plot of average monthly spill from all the cases

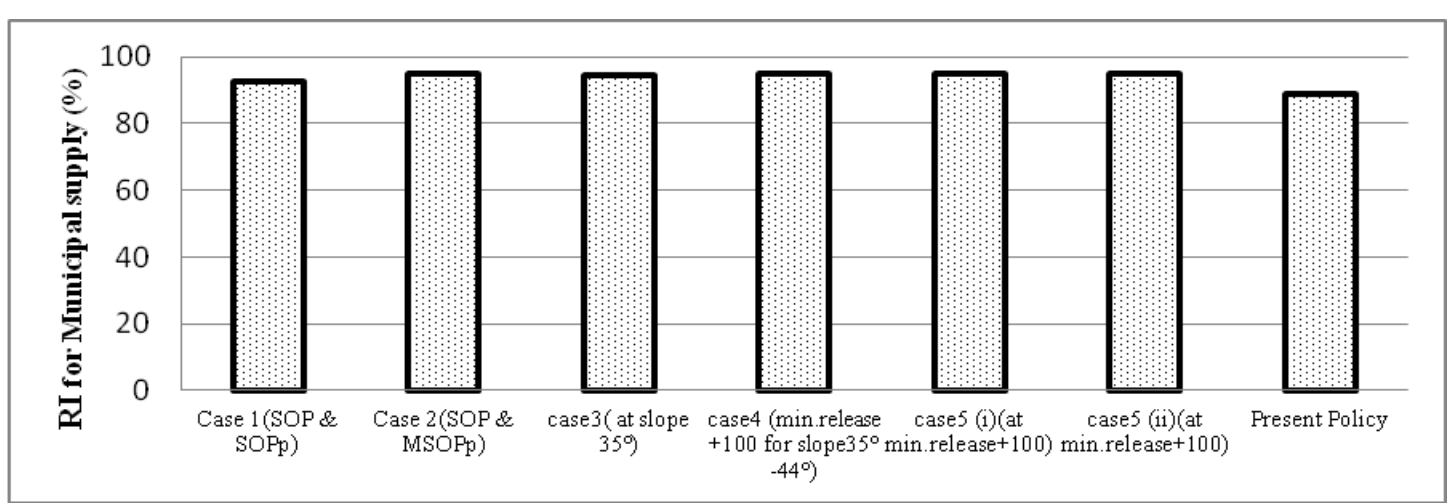

Fig. 11: Comparative plot of RI of municipal supply from all the cases

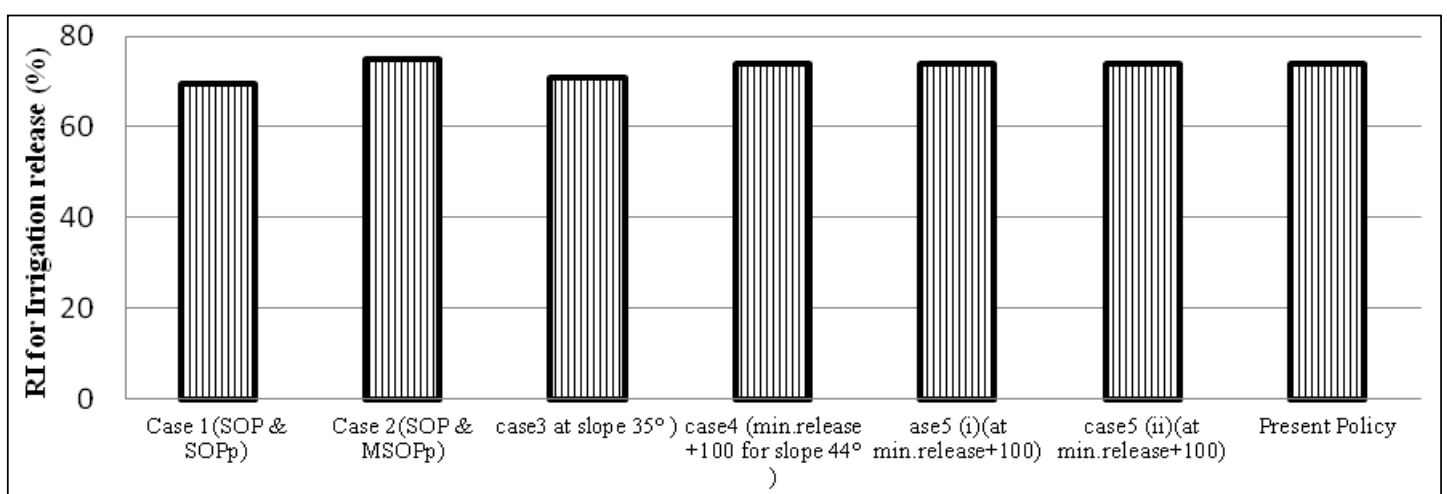

Fig. 12: Comparative plot of RI of irrigation release from all the cases

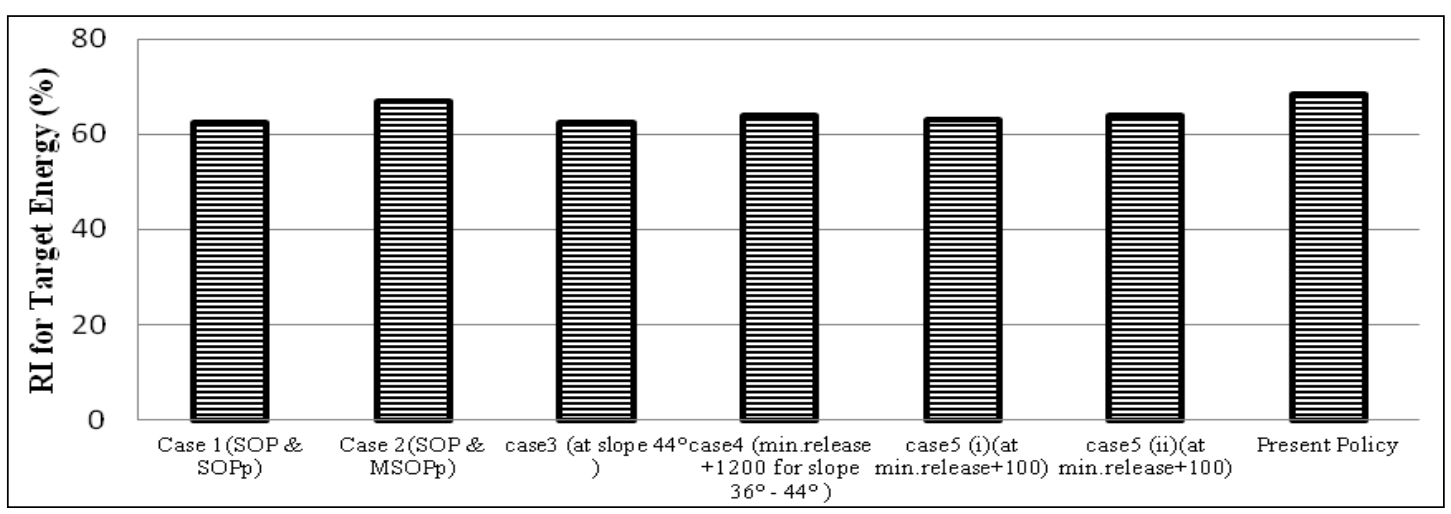

Fig. 13: Comparative plot of RI of target energy from all the cases 


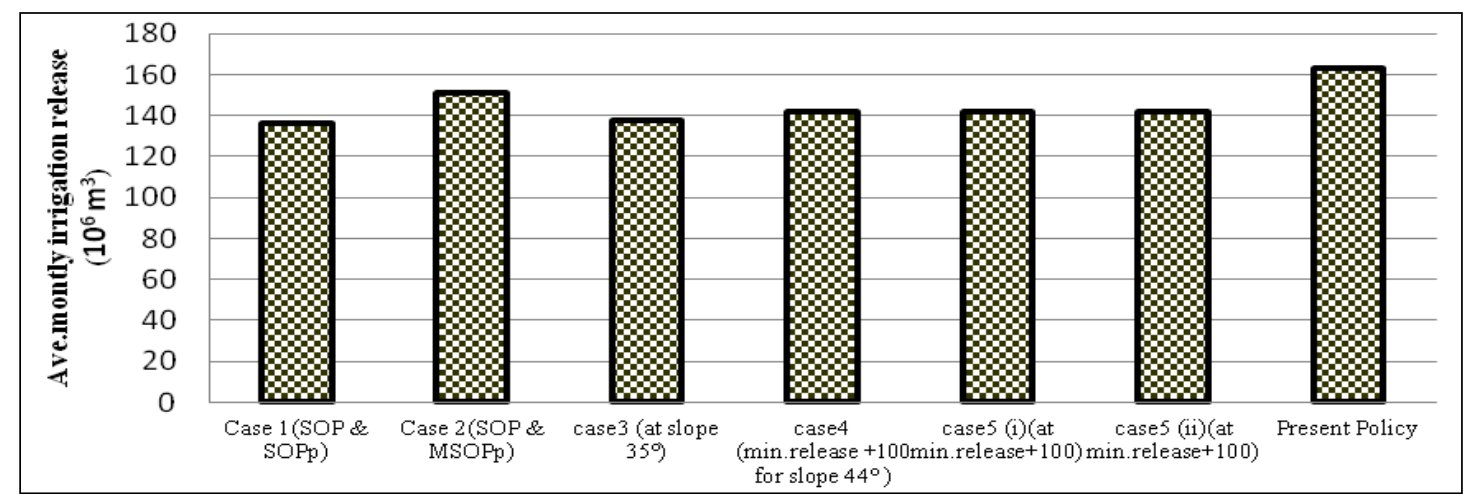

Fig. 14: Comparative plot of average monthly irrigation release from all the cases

\section{Conclusion}

For the past few decades different hedging rules are applied for water supply reservoir operation. Hedging rules for multipurpose reservoir were attempted in this study. One- point hedging rule, modified standard operating policy and standard hedging rules were applied to the operation of the Bargi multipurpose reservoir. The present simulation study indicates that the combined SOP and hedging based policy show improvement in RI of irrigation, RI of target energy production and irrigation release. In this study limited number of hedging rule and limited number of performance indicators were used, hence further research is required to optimize the different hedging rule and their parameter to get a operating rules to improve the performance of the reservoir

\section{References}

[1] K. Srinivasan, T. R. Neelakantan, P. S. Narayan and C. Nagarajukumar, J Water Resour Plan Manag. 125(5), 298 30(1999).

[2] W. W. G. Yeh, Water Resource Research, 21(12), 17971818(1985)

[3] S. P. Simonovic, J Water Resour Plan Manag. 118(3), 262280(1992).

[4] R. Wurbs, J Water Resour Plan Manag. 119(4), 455-472(1993).

[5] J. W. Labadie, J Water Resour Plan Manag. 130(2), 93-111(2004).

[6] B. Celeste, and M. Billib, Advances in Water Resources, 32, 1429 1443(2009).

[7] J. R. Stedinger, Water Resource Research, 20(2), 215-224(1984).

[8] A. J. Draper and J. R. Lund, J Water Resour Plan Manag. 130(1): 83-87(2004).

[9] T. Hashimoto, J. R. Stedinger and D. P. Loucks, Water Resources Research, 18(1), 14-20(1982).

[10] J. S. Shih and C. ReVelle, J Water Resour Plan Manag. 120(5), 613-629(1994).

[11] J. S. Shih and C. ReVelle, Eur J Operational Res 82, 163175(1995).

[12] J. T. Shiau and H. C. Lee, Water Resources Management, 19, $111-$ 132( 2005).

[13] Ming-Yen Tu, Nien-Sheng Hsu, and William, W, -G. Yeh, , J Water Resour Plan Manag. 129(2), 86-97(2003).

[14] T. R. Neelakantan and N. V. Pundarikanthan, Water Resources Management, 13: 409-426(1999).

[15] T. R. Neelakantan and K. Sasireka, International Journal of Engineering and Technology 7(5), 1571-1580 (2015).

[16] K.Sasireka, and T.R Neelakantan Scientia Iranica, 24(5), 2242 2252(2017).

[17] K.Sasireka, and T.R Neelakantan. IOP Conference series: Earth and Environmental Science, 80 (1), 012065 (2017).

[18] M. Karamouz, S. Imen and S. Nazif, Water Resources Management, 26(2), 329-357(2012).

[19] Yun Zeng, Xinyu Wu., Chuntian Cheng, and yuqian Wang, J Water Resour Plan Manag. 10.1061/(ASCE)WR.19435452.0000427(2014).

[20] T. R. Neelakantan and K. Sasireka, International Journal of Engineering and Technology. 5(2), 1191-1196(2013).
[21] S. K. Jain, M. K. Goel, A. R. Senthil Kumar and P. K. Agrawal, (1995-96). Multiobjective optimization of operation of a dam. National Institute of Hydrology, Roorkee, TR (BR) 143, 19951996. 